\section{Another major win for physiotherapy - curing patellofemoral pain}

\author{
Karim M Khan
}

Thanks for the positive feedback about $B J S M$ 's recent articles - particularly the January (http://bjsm.bmj.com/content/ vol43/issue1) and February (http://bjsm. bmj.com/content/vol43/issue2) issues edited by Professor Steven Blair. Many emails supported the claims that physical activity is the most powerful single medical intervention. ${ }^{1}$ The downside is that Neville Owen has made me feel guilty if I sit for a mere 12 hours. $^{2}$ The result? Ageing BJSM editor shuffling around the streets of Vancouver at $10 \mathrm{pm}$ getting his "fix" in $3^{\circ} \mathrm{C}$ temperatures. The voices of Steven Blair and Art Kramer in my head ${ }^{3}$ penetrating the usual cacophony, "30-60 minutes a day keeps dementia at bay". "Too late!" you say?

\section{MAKING PFJ PAIN HISTORY}

Coincidentally with this month's cover story, we learn that Jenny McConnell received Australia's highest honour - the Order of Australia Medal (OAM) — for her "service to physiotherapy as a practitioner and researcher, particularly through the development of innovative musculoskeletal pain management and treatment". Her cataclysmic 1986 paper $^{4}$ timestamps the revolution in managing patellofemoral pain with a focused exercise programme. Young clinicians will have trouble imagining patients hobbled with chronic anterior knee pain being told to "retire" (the 1970s panacea for musculoskeletal pain). The more "enlightened" solution was referral for surgeries ranging from "lateral release" to the gruesome "Macquet procedure". Most unfortunately, one unsatisfied surgical patient actually shot a medical receptionist, ostensibly because of the frustration of chronic knee pain. I apologise for resurrecting painful memories but do so neither flippantly nor gratuitously. I underscore the serious nature of our clinical work and the importance of innovations that improve patients' quality of life.

Correspondence to: Dr Karim M Khan, Professor UBC, Centre for Hip Health and Mobility, Suite 320 - 5950 University Blvd, Vancouver V6T 1Z3, Canada; karim. khan@familymed.ubc.ca
By providing solutions, physiotherapists, and subsequently enlightened physicians, have reframed patellofemoral pain from a static, degenerative condition to one that results from dynamic "malalignment" or "timing failure". I see parallels with Paul Hodges' and others changing our perception of the spine from being a "structural stack" to a finely tuned cylinder and much more. ${ }^{5}$

This month, BJSM shares Collins and colleagues' paper from the BMJ (see page 169), ${ }^{6}$ which investigated a common clinical combination - exercise prescription plus orthoses - for patellofemoral pain. And on the subject of orthoses, please see the evidence-based guide to prescribing running shoes (see page 159).

\section{ACLS, MSCS AND THE I-TEST: ALPHABET} SOUP FOR THE SPORTS MEDICINE SOUL

The scourge of preventable ACL injuries remains ever-present.' If your daughter's basketball or soccer team is not engaged in preventive programmes, ${ }^{78}$ speak to the coach and if that doesn't work call your Member of Parliament. Still no good? Consider the World Court (officially known as the International Court of Justice http://www.icj-cij.org). This is serious. You wouldn't send your kid out cross-country skiing mid-winter in a bikini. Prevention is based on understanding mechanisms and this month we learn about knee joint laxity and its changes during phases of the menstrual cycle from the renowned McCaig Centre at the University of Calgary (see page 174). ${ }^{9}$ And in keeping with Obama's potentiating stem cell research in the US, (see pages 195 and 221 $)^{10} 11$ we examine exercise influences on multipotential stem cells (the MSCs above). Physical activity influences everything!

You'll love the I-test - BJSM's new imaging feature (see pages 172 and 173).$^{12}{ }^{13}$ It vivifies BJSM's commitment to (a) innovation (research), (b) education (Itest and e-learning) and (c) knowledge translation - highlighting programmes that work. I thank editor colleague Dr Babette Pluim (The Netherlands) and Professor Bruce Forster (Canada) for giving
$B J S M$ readers superb educational value. (see page 158); The questions and answers are on different pages to facilitate your placing friendly bets.

\section{CHRONIC GROIN PAIN: LIKELY COMPLETELY SOLVED DURING 2009}

This month's cover pays homage to $\mathrm{Da}$ Vinci's Vitruvian Man (AD 1487) and (http://bjsm.bmj.com/current.dtl) maintains the thread of our virtual theme issue (articles every month) on groin pain. Last month we launched the 3-part "3G" series groins, gluteals and the greater trochanter as a novel clinical approach to chronic groin pain. ${ }^{14}$ Does that pathoanatomical approach simplify it for you? Or are you an advocate of Holmich's tests, ${ }^{16}{ }^{17}$ or the Bradshaw camp? ${ }^{18}$ Let's hope that advances for patients soon match up to those we have seen for patellofemoral pain. And next month? Guest editor Dr Jill Cook brings you BJSM's tendinopathy issue. Please see the new-look homepage and blog for more news! (http://blogs.bmj.com/bjsm/)

Competing interests: None declared.

Br J Sports Med 2009;43:157-158.

doi:10.1136/bjsm.2009.058453

\section{REFERENCES}

1. Blair SN. Physical inactivity: the biggest public health problem of the 21st century. Br J Sports Med 2009;43:1-2.

2. Owen N, Bauman A, Brown W. Too much sitting: a novel and important predictor of chronic disease risk? Br J Sports Med 2009;43:81-3.

3. Erickson KI, Kramer AF. Aerobic exercise effects on cognitive and neural plasticity in older adults. Br J Sports Med 2009;43:22-4.

4. McConnell J. The management of chondromalacia patellae: a long-term solution. Aus J Physio 1986;32:215-23.

5. Hodges $\mathbf{P}$. Transversus abdominis: a different view of the elephant. Br J Sports Med 2008;42:941-4.

6. Collins N, Crossley K, Beller E. Foot orthoses and physiotherapy in the treatment of patellofemoral pain syndrome: randomised clinical trial. Br J Sports Med 2009;43:169-71.

7. Renstrom $\mathbf{P}$, Ljungqvist $A$, Arendt $E$, et al. Noncontact ACL injuries in female athletes: an International Olympic Committee current concepts statement. Br J Sports Med 2008;42:394-412.

8. Soligard T, Myklebust G, Steffen K, et al. Comprehensive warm-up programme to prevent injuries in young female footballers: cluster randomised controlled trial. BMJ 2008;337:a2469

9. Park S-K, Stefanyshyn DJ, Ramage B, et al. Relationship between knee joint laxity and knee joint mechanics during the menstrual cycle. Br J Sports Med 2009;43:174-9.

10. Schmidt A, Bierwirth S, Weber S, et al. Short intensive exercise increases the migratory activity of mesenchymal stem cells. Br J Sports Med 2009;43:195-8.

11. Lucia A, De La Rosa A, Avila Silván M, et al. Mobilisation of mesenchymal cells in cardiac patients: is intense exercise necessary? Br J Sports Med 2009:43:221-3.

12. Waterhouse J, King CR, Chin P, et al. A 61-year-old man with pain in antecubital fossa after an elbow hyperextension injury. Br J Sports Med 2009;43:172. 
13. Mann SA, Leith JM, White JH, et al. Elderly woman with post-traumatic locked shoulder. Br J Sports Med 2009:43:173

14. Falvey E, Franklyn-Miller A, McCrory P. A 3 G approach to a 3-dimensional problem. Br J Sports Med 2009;43:145.

15. Falvey EC, Franklyn-Miller A, McCrory PR. The greater trochanter triangle; a pathoanatomic approach to the diagnosis of chronic, proximal, lateral, lower pain in athletes. Br J Sports Med 2009;43:146-52.

16. Holmich P. Long-standing groin pain in sportspeople falls into three primary patterns, a "clinical entity" approach: a prospective study of 207 patients. Br J Sports Med 2007;41:247-52; discussion 252.
17. Holmich P, Holmich LR, Bjerg AM. Clinical examination of athletes with groin pain: an intraobserver and interobserver reliability study. Br J Sports Med 2004:38:446-51.

18. Bradshaw CJ, Bundy M, Falvey E. The diagnosis of longstanding groin pain: a prospective clinical cohort study. Br J Sports Med 2008;42:551-4.

\section{I-test: a new clinical education feature for the British Journal of Sports Medicine}

\section{Bruce B Forster}

As part of the British Journal of Sports Medicine's (BJSM) emphasis on continuing clinical education, we launch the imaging education feature- "I-test" (imaging test). Each I-test will consist of a short history, key physical examination findings and imaging findings that are needed to arrive at a diagnosis. Images will reflect the breadth of clinical practice and include plain radiographs, ultrasound, computed tomography (CT) and magnetic resonance imaging (MRI). We will emphasise clinical utility-common conditions in which selection of the correct imaging test and interpretation of it will improve patient outcome.

This timely feature is a response to our reader surveys. Imaging continues to be a mainstay in the diagnostic work-up of sports-related injuries. In the US Medicare population, there was a $26 \%$ increase in the use of musculoskeletal imaging techniques from 1996 to $2005 .{ }^{1}$ However, in that same time period, the increase for

Correspondence to: Bruce B Forster, University of BC, Department of Radiology, UBC Hospital, 2211 Wesbrook Mall, Vancouver, BC, Canada V6T 2B5; bruce.forster@ vch.ca musculoskeletal MRI examinations was 354\% and for musculoskeletal ultrasound examinations it was 200\%. ${ }^{1}$ Digital radiographs, ultrasound, CT and MRI are increasingly being ordered by primary care physicians, and are viewed directly by sports physicians, physiotherapists, orthopaedic surgeons, rehabilitation specialists and other related practitioners.

Furthermore, the pace of new developments in musculoskeletal imaging is unrelenting. Ultrasound offers dynamic imaging examination of the musculoskeletal system without ionising radiation, provides important physiological information through colour Doppler and can guide therapeutic intervention. ${ }^{2}$ Multidetector CT is capable of the rapid acquisition of a volume or block of anatomy, which can then be reconstructed in any plane or in three dimensions, to facilitate a better understanding of osseous spatial relationships, detect occult fractures and optimise preoperative planning. ${ }^{3}$ Even recent graduates will be astounded by the numerous advances in MRI. Examples include the clinical reality of high field imaging with $3.0 \mathrm{~T}$, which allows higher spatial resolution for better evaluation of smaller structures, ${ }^{4}$ and also cutting edge physiological cartilage assessment with T1 and T2 mapping, which reveals chondral degeneration before it is apparent clinically or by using other imaging modalities. ${ }^{5}$

BJSM's I-test feature is designed to be practical. It aims to provide value to sports clinicians by illustrating the important synergy between radiology and the management of sports-related injuries. We invite BJSM readers to highlight clinical areas of interest (e-mail the editorial office directly at bjsm@ bmjgroup.com) and to consider submitting a manuscript for this feature (see Instructions for authors).

So please, give your eyes an I-test!

Competing interests: None.

Accepted 26 January 2009

Br J Sports Med 2009;43:158.

doi:10.1136/bjsm.2009.057943

\section{REFERENCES}

1. Parker L, Nazarian LN, Carrino JA, et al. Musculoskeletal imaging: Medicare use, costs, and potential for cost substitution. J Am Coll Radiol 2008;5:182-8.

2. Nazarian L. The top 10 reasons musculoskeletal sonography is an important complementary technique to MRI. AJR Am J Roentgenol 2008;190:1621-6.

3. Geijer M, El-Khoury GY. MDCT in the evaluation of skeletal trauma: principles, protocols, and clinical applications. Emerg Radiol 2006;13:7-18.

4. Meyer JS, Jaramillo D. Musculoskeletal MR imaging at 3T. Magn Reson Imaging Clin N Am 2008;16:533-45.

5. Bining HJS, Santos R, Andrews GT, et al. Can T2 relaxation values and color maps be used to detect chondral abnormality utilizing subchondral bone marrow edema as a marker of chondral damage? Skel Radiol. Published Online First: 20 December 2008. doi: 10.1007/s00256-008-0633-2 